\title{
Effects of cessation of terbutaline treatment on airway obstruction and responsiveness in patients with chronic obstructive pulmonary disease
}

\author{
Jan W de Jong, Gerard H Koëter, Thomas W van der Mark, Dirkje S Postma
}

\begin{abstract}
Background - Cessation of regular therapy with inhaled $\beta_{2}$ agonists in patients with asthma may lead to a temporary deterioration of lung function and airway responsiveness. Few such studies have been reported in patients with chronic obstructive pulmonary disease (COPD), so an investigation was carried out to determine whether rebound airway responsiveness and rebound bronchoconstriction also occurs in COPD and if there is any relationship with the dose of $\beta_{2}$ agonist being used.
\end{abstract}

Methods - Lung function (forced expiratory volume in one second $\left(F E V_{1}\right)$ and peak expiratory flow (PEF)), airway responsiveness $\left(\mathbf{P C}_{20}\right.$ methacholine $\left.\left(\mathbf{P C}_{20}\right)\right)$ and symptoms were assessed in a double blind, placebo controlled crossover study during and after cessation of two weeks regular treatment with placebo, and low dose $(250 \mu \mathrm{g})$ and high dose $(1000 \mu \mathrm{g})$ inhaled terbutaline via a dry powder inhaler (Turbohaler) all given three times a day. Sixteen non-allergic patients with COPD of mean (SD) age $58.7(6.5)$ years, FEV $_{1}$ $57 \cdot 1(12 \cdot 8) \%$ of predicted, and reversibility on $1000 \mu \mathrm{g}$ terbutaline of $4.5(3.5) \%$ predicted were studied. $\mathbf{P C}_{20}$ and $\mathbf{F E V} \mathrm{V}_{1}$ were measured 10, 14, 34 and 82 hours after the last inhalation of terbutaline or placebo. Measurements performed at 10,14, and 34 hours were expressed relative to 82 hour values in each period, transformed into an area under the curve (AUC) value and analysed by ANOVA.

Results - Mean morning and evening PEF increased during terbutaline treatment. $P_{20}$ and $F E V_{1}$ did not change after cessation of terbutaline treatment.

Conclusions - Cessation of regular treatment with both low and high dose inhaled terbutaline does not result in a rebound bronchoconstriction and rebound airway responsiveness in patients with COPD. (Thorax 1996;51:684-688)

Keywords: terbutaline, rebound airway responsiveness, rebound bronchoconstriction, chronic obstructive pulmonary disease.

The regular use of high doses of $\beta_{2}$ agonists has been shown to be an important risk factor for morbidity and mortality in asthma. ${ }^{1}$ Adverse effects of $\beta_{2}$ agonists in asthma may be demonstrated in the occurrence of rebound airway responsiveness or rebound bronchoconstriction after cessation of regular $\beta_{2}$ agonist therapy in some studies. ${ }^{23}$ Bronchodilator therapy has generally been accepted as an important mainstay in the treatment of chronic obstructive pulmonary disease (COPD), and single inhalations of both $\beta_{2}$ adrenergic agonists and anticholinergic drugs have been shown to induce short term improvement in forced expiratory volume in one second $\left(\mathrm{FEV}_{1}\right) .{ }^{4}$ Even with little bronchodilator effect, symptoms and exercise tolerance may improve. However, studies investigating the effects of regular bronchodilator treatment in COPD are scarce and, what is more, they show both advantages and disadvantages of bronchodilator treatment on decline of $\mathrm{FEV}_{1}{ }^{56}$ As cessation of regular $\beta_{2}$ agonist therapy may induce rebound airway responsiveness and rebound bronchoconstriction in asthma, we questioned whether this may also occur after cessation of regular $\beta_{2}$ agonist therapy in patients with COPD. As far as we are aware, no such studies have been published in patients with COPD so we investigated the occurrence of rebound airway responsiveness and rebound bronchoconstriction after cessation of regular treatment with terbutaline in non-allergic patients with COPD. As this effect may be dose dependent, patients inhaled both a low dose $(250 \mu \mathrm{g}$ three times daily) and a high dose of terbutaline (1000 $\mu \mathrm{g}$ three times daily) for two weeks.

\section{Methods}

PATIENTS

All patients with COPD selected for this study met the following inclusion criteria: (1) age 45 years or older, current or former smokers without a history of asthmatic attacks, presence of either chronic cough with or without sputum production or dyspnoea when walking quietly on level ground, or both, ${ }^{7}$ and no other major diseases; (2) no atopy, defined by negative skin tests (Diephuis Laboratories, Groningen, The Netherlands), no detectable specific serum immunoglobulin $\mathrm{E}$ (IgE) to house dust mite (HDM), and total serum IgE within normal levels; (3) forced expiratory volume in one second $\left(\mathrm{FEV}_{1}\right)$ of $>1$ litre and, after inhalation of $1000 \mu \mathrm{g}$ terbutaline via a multidose dry powder delivery system (Turbuhaler, Astra Draco, Lund, Sweden), $<85 \%$ predicted with an ab- 


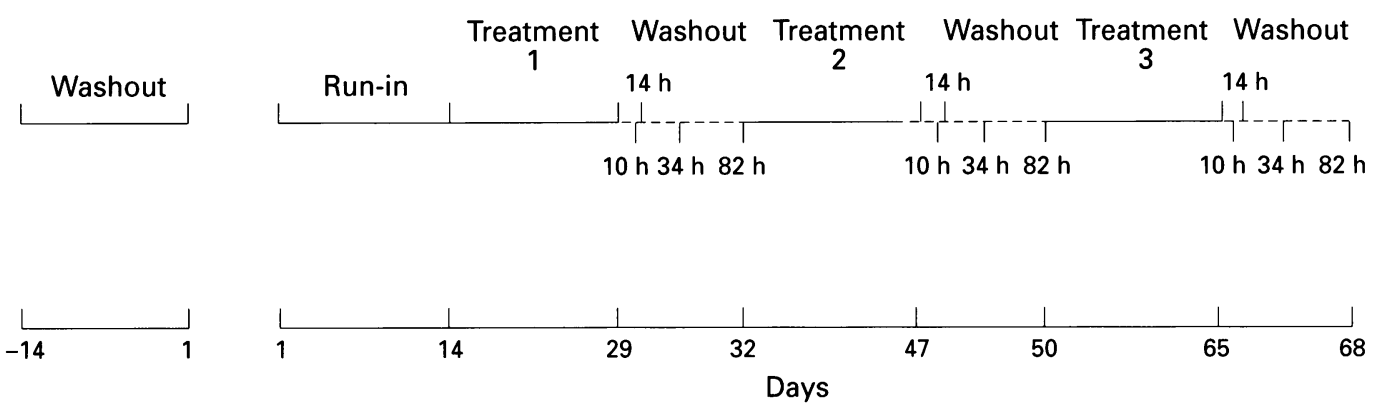

Figure 1 Study design. Numbers 1, 2, and 3 represent the treatment periods with placebo, terbutaline $250 \mu g$, or terbutaline $1000 \mu \mathrm{g}$ three times daily in random order. During the washout periods all patients with COPD used only ipratropium bromide on demand.

solute increase in $\mathrm{FEV}_{1}$ of $<9 \%$ predicted; (4) concentration of methacholine causing a $20 \%$ decrease in $\mathrm{FEV}_{1}$ from baseline $\left(\mathrm{PC}_{20}\right)$ of $<4 \mathrm{mg} / \mathrm{ml}$; (5) no upper respiratory tract infection or exacerbation of their airways disease within six weeks of starting the study. The study was approved by the hospital medical ethics committee and all subjects gave their written informed consent to participate.

\section{STUDY DESIGN}

The study was of a double blind crossover design and lasted for 10 weeks (fig 1). After a 14 day run-in period patients were randomised in a double blind manner to three 14 day treatment periods: $250 \mu \mathrm{g}$ terbutaline (low dose terbutaline), $1000 \mu \mathrm{g}$ terbutaline (high dose terbutaline), or placebo, all given three times a day and each followed by a four day washout period. Methacholine challenges were performed 10, 14, 34, and 82 hours after the last dose of terbutaline or placebo. Terbutaline $(250 \mu \mathrm{g}$ and $500 \mu \mathrm{g}$ doses) and matching placebos were administered by a Turbohaler. The use of inhaled corticosteroids was stopped at least two weeks before the start of the study; oral corticosteroids, nedocromil sodium, sodium cromoglycate, antihistamines, or bronchodilators were not used. During the study all patients were allowed to use ipratropium bromide (Atrovent, Boehringer Ingelheim, Germany) from an Inhalet inhaler for symptomatic relief, but not within 12 hours before the methacholine challenges and not within six hours before peak flow (PEF) measurements. All patients kept daily diary cards throughout the study on which they recorded daytime and night time respiratory symptom scores using a four point severity scale $(0=$ no symptoms, $3=$ severe symptoms), the number of ipratropium bromide inhalations during the day and night, the number of inhalations from the inhalers, and the highest of three measurements of morning and evening PEF using the mini-Wright peak flow meter (Clement Clarke International Ltd, London, UK).

\section{BRONCHIAL PROVOCATION}

Spirometric tests were performed using a calibrated water sealed spirometer (Lode BV, Groningen, The Netherlands) according to standardised guidelines. Reference values are those of the European Community for Coal and Steel. ${ }^{8}$

A solution of methacholine bromide was administered as an aerosol generated from a starting volume of $3 \mathrm{ml}$ in a DeVilbiss 646 nebuliser (DeVilbiss Co, Somerset, Pennsylvania, USA) connected to the central chamber of an inspiratory-expiratory valve box (BPA type $2 \mathrm{~V}$ ). Air pressure was adjusted to 1 bar using a pressure gauge (Porter, Type 8286) and a rotameter (Hoekloos, Type 30277) to establish a regularly calibrated solution output of $0.13 \mathrm{ml} /$ min. After inhalation of $0.9 \%$ sodium chloride and at five minute intervals, subjects inhaled doubling concentrations of methacholine bromide for two minutes, ranging from 0.038 to $314 \mathrm{mg} / \mathrm{ml}^{9}{ }^{9} \mathrm{FEV}_{1}$ was measured 30 and 90 seconds after each inhalation until it was less than $80 \%$ of the prechallenge value. $\mathrm{A} \mathrm{PC}_{20}$ value of 0.015 was assigned to each patient already responding to saline. $\mathrm{PC}_{20}$ values were determined by linear interpolation between the last two data points on the logarithmic concentration-response curve. $\mathrm{PC}_{20}$ values were analysed after base 2 logarithmic transformation, one log unit being one dose step in concentration.

\section{DATA ANALYSIS}

Differences in $\mathrm{PC}_{20}$ and $\mathrm{FEV}_{1}$ measured at 10 , 14 , and 34 hours after the last terbutaline or placebo inhalation were calculated relative to the values measured at 82 hours after the last terbutaline or placebo inhalation. $\mathrm{PC}_{20}$ and $\mathrm{FEV}_{1}$ values were then transformed to one single area under the curve (AUC) value as calculated by trapezoidal method using identical intervals between measurements. For all AUC values a $t$ test was used to calculate whether the AUC was different from zero. Rebound airway responsiveness and rebound bronchoconstriction were defined as the difference in AUC-PC 20 and AUC-FEV 1 measured after the last terbutaline inhalation compared with the AUC-PC ${ }_{20}$ and AUC-FEV 1 after the last placebo inhalation. Mean AUC-PC 20 and $\mathrm{AUC}-\mathrm{FEV}_{1}$ values were compared by means of a fixed effects analysis of variance (ANOVA) with the factors patient, treatment (placebo, low dose terbutaline and high dose terbutaline) and period. Repeated measures ANOVA were performed on $\mathrm{PC}_{20}$ and $\mathrm{FEV}_{1}$ after the run-in period with day $14,32,50$, 
Table 1 Individual patient characteristics

\begin{tabular}{|c|c|c|c|c|c|c|}
\hline Subject no. & $\begin{array}{l}\text { Smoking } \\
\text { (current or ex) }\end{array}$ & $\begin{array}{l}\text { Age } \\
\text { (years) }\end{array}$ & Sex & $\begin{array}{l}\text { Reversibility** } \\
\text { ( } \triangle F E V_{1} \% \text { pred) }\end{array}$ & $\begin{array}{l}F E V_{1} \\
\text { (\% pred) }\end{array}$ & $\begin{array}{l}P C_{20} \text { methacholine } \\
(\mathrm{mg} / \mathrm{ml})\end{array}$ \\
\hline 1 & Ex & 62 & $M$ & $8 \cdot 0$ & $65 \cdot 5$ & 1.68 \\
\hline 2 & Ex & 55 & $M$ & $6 \cdot 7$ & $49 \cdot 2$ & 1.03 \\
\hline 3* & Ex & 71 & $M$ & $8 \cdot 4$ & $45 \cdot 8$ & 0.27 \\
\hline 4 & Current & 52 & M & $2 \cdot 0$ & $35 \cdot 0$ & 0.03 \\
\hline 5 & Current & 66 & M & $3 \cdot 1$ & $63 \cdot 6$ & 1.56 \\
\hline 6 & Current & 49 & M & $8 \cdot 6$ & $71 \cdot 8$ & 1.97 \\
\hline 7 & Ex & 61 & $M$ & $4 \cdot 1$ & 58.9 & 1.86 \\
\hline 8 & Ex & 58 & $\mathrm{~F}$ & $3 \cdot 8$ & 70.9 & 0.61 \\
\hline 9 & Current & 52 & M & $3 \cdot 7$ & $59 \cdot 4$ & 0.40 \\
\hline $10^{*}$ & Current & 50 & $\mathrm{~F}$ & 0 & $67 \cdot 1$ & 0.61 \\
\hline 11 & Current & 62 & $\mathrm{~F}$ & $-2 \cdot 0$ & $62 \cdot 3$ & 0.31 \\
\hline 12 & Ex & 68 & $M$ & 8.5 & $47 \cdot 3$ & 0.31 \\
\hline $13^{*}$ & Ex & 60 & $\mathrm{~F}$ & $7 \cdot 4$ & $68 \cdot 5$ & 1.86 \\
\hline 14 & Current & 62 & M & $2 \cdot 2$ & $57 \cdot 1$ & 1.04 \\
\hline $15^{*}$ & Current & 53 & $\mathrm{~F}$ & $7 \cdot 2$ & $62 \cdot 5$ & $0 \cdot 15$ \\
\hline & Current & 58 & $M$ & $-0 \cdot 6$ & $28 \cdot 0$ & 0.59 \\
\hline \multicolumn{2}{|l|}{ Mean (SD) } & \multicolumn{2}{|c|}{$58 \cdot 7(6 \cdot 5)$} & $4.5(3.5)$ & $57 \cdot 1(12 \cdot 8)$ & $0.6 \dagger$ \\
\hline
\end{tabular}

$\mathrm{FEV}_{1}$ = forced expiratory volume in one second.

* Patients who did not complete the study.

† Geometric mean.

** After $1000 \mu \mathrm{g}$ terbutaline per Turbohaler.

and 68 - that is, 82 hour time points (fig 1) as within subject factors in order to study the overall time effect. ANOVA was also used to check the presence of any period or carryover effect.

Diary card data were based on the mean of the data over the last 10 days of each treatment period. PEF variability was expressed as the diurnal peak flow variation: (evening reading morning reading)/mean of these two readings $\times 100 \%$. All diary card data were analysed with ANOVA. A difference of 1.0 doubling dose step in rebound airway responsiveness after treatment was supposed to be clinically significant. From earlier studies the standard deviation of $\mathrm{PC}_{20}$ was found to be 1.0 doubling dose step. Taking $\alpha=0.05$ and $\beta=0.20$, the sample sizes of 12 patients with COPD were derived. Two tailed tests have been used throughout at the $95 \%$ level of significance. All analyses were performed with the SAS 6.04 for Windows package. ${ }^{10}$

\section{Results}

Sixteen patients with COPD participated in the study (table 1). Four patients were withdrawn, three because of a respiratory tract infection (subject 3 (period 3), subject 13 (run-in), and subject 15 (period 1)), and one (subject 10) was not included in the analyses as she showed evidence of atopy during the study. Periods 1 and 2 of subject 3 were included for statistical analysis. Eight patients had been previously treated with inhaled corticosteroids. There were no statistically significant period and carryover effects.

CHANGE IN AIRWAY RESPONSIVENESS (fig 2)

Mean $\mathrm{PC}_{20}$ values did not change significantly at day 14 or at all subsequent days of measurement - that is, 82 hours after the last inhalation of placebo or terbutaline. The $\mathrm{PC}_{20}$ methacholine increased at day 14 compared with the run-in value, but this was not significant. There was no significant difference between the three AUC-PC 20 values after cessation of placebo, low dose terbutaline, and high dose terbutaline.
All three AUC-PC ${ }_{20}$ values did not differ significantly from zero.

CHANGE IN FEV 1 (fig 3)

At day 14 and on all subsequent days of measurement - that is, 82 hours after the last inhalation of placebo or terbutaline - mean $\mathrm{FEV}_{1}$ values did not change significantly. $\mathrm{FEV}_{1}$ significantly decreased at day 14 compared with the run-in value $(p<0.05)$. There was no significant difference between the three AUC$\mathrm{FEV}_{1}$ values after cessation of placebo, low dose terbutaline, and high dose terbutaline. All three AUC-FEV 1 values did not differ significantly from zero.

PEF, SYMPTOM SCORES, IPRATROPIUM BROMIDE USE AND ADVERSE EFFECTS (tables 2 and 3 )

Mean morning and evening PEF values were significantly higher during treatment with low dose and high dose terbutaline than during the

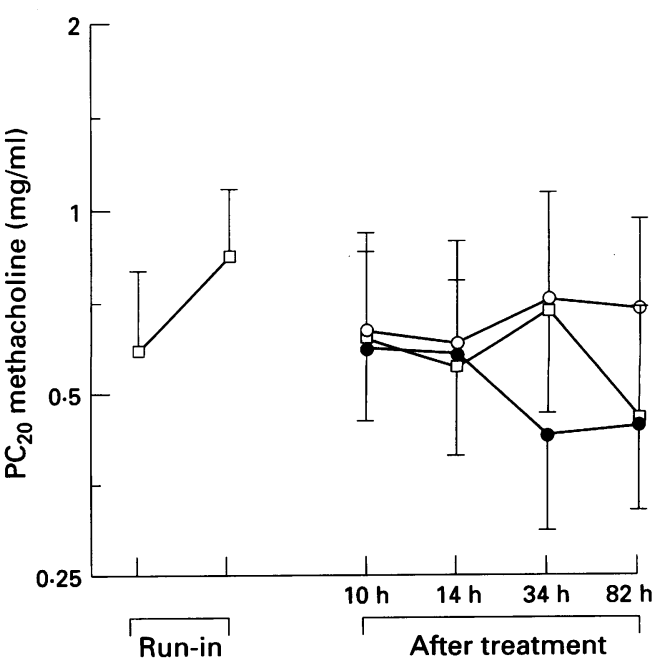

Figure 2 Changes in $P C_{20}$ methacholine after cessation of placebo ( $\square$ ), low dose terbutaline ( $250 \mu \mathrm{g}$ three times daily, O), and high dose terbutaline (1000 $\mu \mathrm{g}$ three times daily, ). Data are expressed as mean (SE) of $\log _{2}$ transformed data. The order of treatments was randomised. 


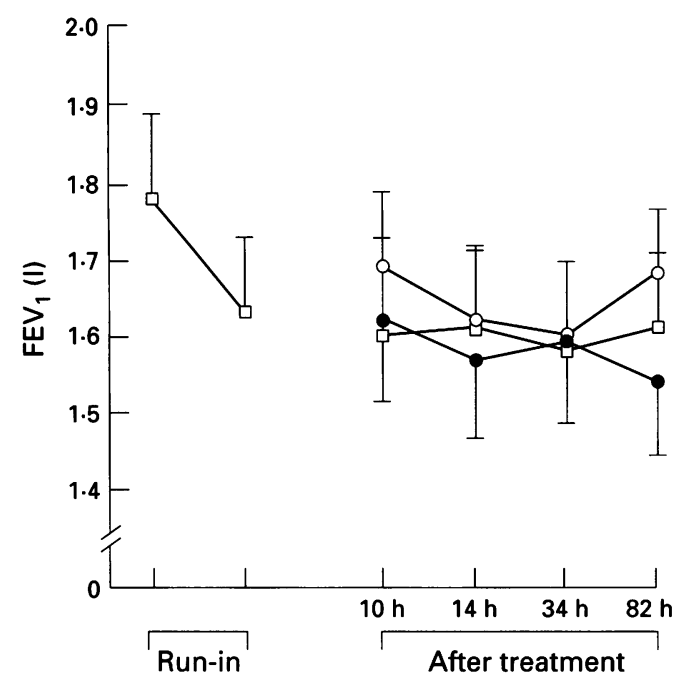

Figure 3 Changes in FEV, after cessation of placebo

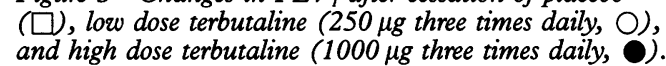
Data are expressed as mean (SE). The order of treatments was randomised.

Table 2 Mean (SD) peak flow measurements

\begin{tabular}{lll}
\hline & $\begin{array}{l}\text { Morning PEF } \\
\text { (l/min) }\end{array}$ & $\begin{array}{l}\text { Evening PEF } \\
\text { (l/min) }\end{array}$ \\
\hline Run-in & $313 \cdot 5(60 \cdot 1)$ & $322 \cdot 0(68 \cdot 9)$ \\
Placebo & $306 \cdot 6(63 \cdot 2)$ & $318 \cdot 2(67 \cdot 4)$ \\
Low dose terbutaline & $327 \cdot 2(63 \cdot 5)^{* *}$ & $340 \cdot 2(70 \cdot 1)^{* *}$ \\
High dose terbutaline & $329 \cdot 8(65 \cdot 9)^{* *}$ & $343 \cdot 8(70 \cdot 6)^{* *}$ \\
\hline
\end{tabular}

${ }^{* *} \mathrm{p}<0.01$ compared with placebo values.

Table 3 Mean (SE) diurnal variation in PEF, ipratropium bromide use and symptom scores

\begin{tabular}{llll}
\hline & $\begin{array}{l}\text { Diurnal PEF } \\
\text { variation }(\%)\end{array}$ & $\begin{array}{l}\text { Ipratropium bromide use } \\
\text { (no. of inhalations) }\end{array}$ & $\begin{array}{l}\text { Symptom } \\
\text { scores* }\end{array}$ \\
\hline Run-in & $2 \cdot 1(1 \cdot 8)$ & $1 \cdot 5(0 \cdot 5)$ & $1 \cdot 2(0 \cdot 3)$ \\
Placebo & $3 \cdot 4(2 \cdot 6)$ & $1 \cdot 5(0 \cdot 5)$ & $1.4(0 \cdot 3)$ \\
Low dose terbutaline & $3 \cdot 6(1 \cdot 4)$ & $1 \cdot 3(0 \cdot 5)$ & $1.4(0 \cdot 4)$ \\
High dose terbutaline & $3.9(2 \cdot 0)$ & $1 \cdot 1(0.4)$ & $1.4(0 \cdot 3)$ \\
\hline
\end{tabular}

* Symptoms were scored on a four point scale where $0=$ no symptoms and $3=$ severe symptoms.

placebo period $(\mathrm{p}<0 \cdot 01)$. Diurnal variation in PEF and symptom scores did not change. The use of ipratropium bromide escape therapy tended to decrease during terbutaline treatment. Adverse effects during the study were negligible.

\section{Discussion}

Cessation of regular treatment with inhaled terbutaline $250 \mu \mathrm{g}$ and terbutaline $1000 \mu \mathrm{g}$ three times daily for two weeks in non-allergic patients with COPD did not result in a significant rebound airway responsiveness or in rebound bronchoconstriction. On the contrary, mean morning and evening PEF values were significantly higher during treatment with low dose and high dose terbutaline, whereas mean diurnal variation in PEF did not change.

The results of our study suggest that regular use of $\beta_{2}$ agonists is not detrimental in COPD, although our treatment periods lasted no longer than two weeks. This is in contrast to findings in patients with asthma who may show rebound airway responsiveness up to 59 hours and re- bound bronchoconstriction up to 11 hours after stopping regular $\beta_{2}$ agonist treatment. ${ }^{3}$ Betareceptor desensitisation on airway smooth muscles and inflammatory cells has been suggested as a possible mechanism of increased airway responsiveness after cessation of regular $\beta_{2}$ agonist treatment. In addition, continuous bronchodilation itself may increase the amount of antigen load in the lungs, eventually leading to increased airway responsiveness in asthma. An explanation for the absence of rebound airway responsiveness and bronchoconstriction in COPD may be the fact that inflammation of the airway wall in patients with COPD is different from asthma ${ }^{11}$ - for example, mast cells are more prominent in the airway wall of asthmatic subjects than those with COPD, and $\beta_{2}$ receptor desensitisation on mast cells has been thought to play a substantial part in rebound airway responsiveness. ${ }^{1213}$ Rebound phenomena may thus occur as a result of allergic airway inflammation. In a recent study ${ }^{14}$ we have shown that inhaled corticosteroids may protect against the occurrence of rebound bronchoconstriction in patients with allergic asthma. If allergic mechanisms play a part in rebound phenomena, this is not likely to be of significance in the patients in this study with COPD as they were all non-allergic. Furthermore, it has been suggested that $\beta_{2}$ receptor responsiveness may decrease with age. ${ }^{1516}$ As our patients with COPD were older than those in other studies on asthmatic patients, age may partially explain the absence of rebound phenomena in COPD.

In both patients with moderate asthma and those with chronic bronchitis, van Schayck et $a l^{6}$ have shown that regular treatment with bronchodilators (salbutamol $1600 \mu \mathrm{g} /$ day or ipratropium bromide $160 \mu \mathrm{g} /$ day) was associated with a significantly higher annual decline in $\mathrm{FEV}_{1}$ compared with those treated on demand. The difference in decline between the two treatments in patients with chronic bronchitis was comparable with the decline in patients with asthma, although the mean baseline $\mathrm{FEV}_{1}$ in the group of patients treated continuously was considerably lower than in the group of patients treated on demand. As all patients in the study of van Schayck et al stopped bronchodilator treatment at least eight hours before the start of the measurements of $\mathrm{PC}_{20}$ histamine and $\mathrm{FEV}_{1}$, and as a considerable number of patients were allergic, rebound bronchoconstriction may have been partly responsible for the annual decline in $\mathrm{FEV}_{1}$ seen in some of these patients during treatment.with $\beta_{2}$ agonists. In the group of asthmatic patients mean reversibility was high ( $24 \%$ predicted) and $36 \%$ of patients were allergic. However, rebound bronchoconstriction may also have been partly responsible for the annual decline in $\mathrm{FEV}_{1}$ in the patients with chronic bronchitis as some of these patients may also have had asthmatic features: a considerable number were allergic (18\%), were never smokers $(13 \%)$, and had a high mean reversibility of obstruction $(>11 \%$ predicted). van Schayck et $a l^{17}$ recently reported that a fall in $\mathrm{FEV}_{1}$ does not occur when patients with mild asthma and COPD are continuously 
treated with bronchodilators for four years. However, in this study none of the patients was dependent on steroids and the baseline $\mathrm{FEV}_{1}$ did not differ between the patients treated continuously and those treated on demand.

We conclude that cessation of two week regular treatment with a $\beta_{2}$ agonist given in both low and high doses does not lead to rebound airway responsiveness and rebound bronchoconstriction in non-allergic patients with COPD. Long term trials with $\beta_{2}$ agonists are necessary to assess their advantages and disadvantages in the regular treatment of COPD

This study was supported by a research grant from Astra, The Netherlands. We thank Mr M Boorsma for his critical review of the manuscript.

1 Spitzer WO, Suissa S, Ernst P, Horwitz RI, Habbick B, Cockcroft $\mathrm{D}$, et al. The use of $\beta$-agonists and the risk of death and near death from asthma. N Engl f Med 1992; 326:501-6.

2 Vathenen AS, Knox AJ, Higgins BG, Britton JR, Tattersfield $A K$. Rebound increase in bronchial responsiveness after AK. Rebound inces

Wahedna I, Wong CS, Wisniewski AFZ, Pavord ID, TatWersfield AK. Asthma control during and after cessation tersfield AK. Asthma control during and after cessation of regular $\beta$

4 Karpel JP. Bronchodilator responses to anticholinergic and $\beta$-adrenergic agents in acute and stable COPD. Chest 1991;99:871-6.

5 Postma DS, de Vries K, Koëter GH, Sluiter HJ. Independent influence of reversibility of airflow obstruction and nonspecific hyperreactivity on the long-term course of lung function in chronic airflow obstruction. Am Rev Respir Dis $1986 ; 134: 276-80$.
6 van Schayck CP, Dompeling E, van Herwaarden CLA Folgering $\mathrm{H}$. Verbeek ALM, van der Hoogen HJM, et al. Bronchodilator treatment in moderate asthma or chronic bronchitis: continuous or on demand? A randomised controlled study. BMF 1991;303:1426-31.

7 American Thoracic Society. Standards for the diagnosis and care of patients with chronic obstructive pulmonary disease (COPD) and asthma. Am Rev Respir Dis 1987;136:225-44

8 Quanjer PhH. Standardized lung function testing. Bull Eur Physiopathol Respir 1983;19(Suppl 5):7-28.

Sterk PJ, Fabbri LM, Quanjer PhH, Cockcroft DW, O'Byrne PM, Anderson SD, et al. Airway responsiveness. Standardized challenge testing with pharmacological, physical and sensitizing stimuli in adults. Eur Respir f 1993;6 (Suppl 16):53-83.

10 The SAS System for Windows $3 \cdot 10$, release 6.08. Cary, North Carolina, USA: SAS Institute Inc, 1992.

11 Ollerenshaw SL, Woolcock AJ. Characteristics of the inflammation in biopsies from large airways of subjects with asthma and subjects with chronic airflow limitation. $A m$ Rev Respir Dis 1992;145:922-7.

12 Phillips GD, Finnerty JP, Holgate ST Comparative protective effect of the inhaled $\beta_{2}$-agonist salbutamol (albuterol) on bronchoconstriction provoked by histamine, methacholine, and adenosine $5^{\prime}$-monophosphate in asthma. F Allergy Clin Immunol 1990;85:755-62.

13 O'Connor BJ, Aikman SL, Barnes PJ. Tolerance to the nonbronchodilator effects of inhaled $\beta_{2}$-agonists in asthma. N Engl f Med 1992;327:1204-8.

14 de Jong JW, van der Mark ThW, Koëter GH, Postma DS. Rebound airway obstruction and responsiveness after cessation of terbutaline treatment: effects of budesonide. Am 7 Respir Crit Care Med 1996;153:70-5.

15 Nijkamp FP, Engels F, Henricks PAJ, van Oosterhout AJM Mechanisms of $\beta$ adrenergic receptor regulation in lungs and its implications for physiological responses. Physiol and its implications

16 Ullah ML, Newman GB, Saunders K. Influence of age on response to ipratropium and salbutamol in asthma. Thora 1981;36:523-9.

17 van Schayck CP, Dompeling E, van Herwaarden CLA Folgering H, Akkermans RP, van den Broek PJA, et al. Continuous use of bronchodilators versus use on demand in mild asthma and COPD. Am f Respir Crit Care Med 1994;149:A203. 